\title{
Effects of parenting education programs for refugee and migrant parents: a systematic review and meta-analysis
}

\author{
In-Sook Lee ${ }^{1}$, Eunjung Kim ${ }^{2}$ \\ ${ }^{1}$ Associate Professor, Department of Nursing, Hannam University, Daejeon, Korea; ${ }^{2}$ Associate Professor, School of Nursing, University of Washington in Seattle, \\ Washington, USA
}

Purpose: This systematic review and meta-analysis investigated the effects of parenting education programs (PEPs) for refugee and migrant parents. Methods: A systematic review was conducted according to PRISMA guidelines. Relevant studies published from 2000 to 2020 were identified through a systematic search of six electronic databases (PubMed, Embase, Cochrane Library, CINAHL, RISS, KMBASE). A meta-analysis of the studies was then undertaken. Results: Of the 14,996 published works identified, 23 studies satisfied the inclusion criteria, and 19 studies were analyzed to estimate the effect sizes (standardized mean differences) of the PEPs using random-effect models. PEPs were effective for parenting efficacy (effect size [ES] $1.40 ; 95 \%$ confidence interval [CI]: 1.14-1.66), positive parenting behaviors (ES=0.51; 95\% CI: 0.30-0.73), parent-child relationships (ES=0.38; 95\% CI: 0.22-0.53), and parenting stress (ES=0.64; 95\% CI: $0.50-0.79)$. There were statistically significant differences in the effect sizes of PEPs that included mothers only ( $\mathrm{ES}=0.93$ ), included children under 7 years of age(ES=0.91), did not include child participation ( 0.77 ), continued for 19 or more sessions $(\mathrm{ES}=0.80)$, and were analyzed in quasi-experimental studies $(\mathrm{ES}=0.86)$. The overall effect of publication bias was robust. Conclusion: PEPs were found to be effective at improving parenting efficacy, positive parenting behaviors, parent-child relationships, and parenting stress.

Key words: Parenting; Education; Refugees; Transients and migrants; Meta-analysis

\section{Corresponding author}

In-Sook Lee

Department of Nursing, Hannam

University, 70 Hannam-ro, Daedoek-gu,

Daejon 34430, Korea

TEL: +82-42-629-8472

FAX: +82-42-629-8472

E-MAIL: is2009@hnu.kr

Received Oct 18, 2021

Revised Nov 17, 2021

Accepted Nov 24, 2021

\section{INTRO DUCTION}

Refugee and migrant parents, including North Korean refugees, experience elevated psychological and mental stress related to parenting when they are unprepared for their role as they adjust to a new social and cultural environment [1]. The accumulation of this stress directly impacts not only themselves but also their children [2,3]. The socioeconomic status of parents, as well as the family environment, are crucial for children's growth and development since they are affected by parenting attitudes and parenting roles. The growth and development of individuals during childhood, which is the time in life during which a person is most vulnerable, also varies according to formal education [4]. In particular, in an information-oriented society in which a copious amount of unfiltered information about parenting is accessible, effective parenting can be challenging. This challenge is particularly intense for North Korean refugee and migrant parents who tend to be socioeconomically vulnerable, lack information and support systems, and have poor literacy skills with which to identify legitimate information about parenting [5]. A previous study also reported that, although North Korean refugee parents strived to raise their children well, they often lacked specific knowledge and skills related to their roles as parents, indicating that parenting education is needed to address the issue [5].

Parenting education refers to lifelong education for parents that aims to promote desirable and positive changes in parenting [6]. Parenting education is essential since many parents lack opportunities to learn parenting roles naturally, and the need to understand these roles and the consequent burden as parents are rising [4]. Although parents are automatically re- 
quired to take on parental roles once they have children, many parents find it difficult to perform their roles adequately as their children grow. When faced with difficulties or a failure to acclimate properly while raising children, parents may become confused and discipline their children inappropriately, which in turn severs communication between parents and their children and can result in child abuse [4]. Parenting roles are learned and not innate, and it is thus possible to learn effective parenting [7]. Positive transformation of parental roles through parenting education would tremendously benefit children's growth and development [3]. In addition, parental education helps reduce maternal depression and stress, increases parental satisfaction and efficiency, and reduces problems related to parenting [1].

Parenting education aims to promote changes in parenting attitudes and styles to facilitate optimal growth and development in children. Most parenting education programs (PEPs) include practical and theoretical information about children's growth and parenting behaviors. PEPs teach parenting skills through role-play or demonstrations, increase awareness of the effects of parenting behaviors on children's behaviors, and improve the ability of parents to solve or address problems related to their relationships with their children [8,9]. Types of PEPs include social and emotional development programs, physical development programs, academic competence programs, cognitive development programs, and various comprehensive development programs based on child development [6]. Furthermore, PEPs improve parent-child relationships, which are the first social relationships that children form in their lives [10]. A secure parent-child relationship supports the development of positive relationships with others in children and plays a crucial role in children's growth, development, and environmental adjustment [10]. Therefore, family counseling and parenting education focus on transforming interactions between family members and promoting the functioning of the family as a unit [8]. Parenting education for multicultural families and refugee or immigrant mothers should be structured to provide adequate information about the roles of parents according to the developmental stage of children and offer information about the use of community services for practical assistance [10]. Many PEPs for migrants or refugees have been found to alter parenting behaviors and reduce parents' emotional stress, thereby promoting growth and development in children [11-13]. Several studies have been conducted on this subject, including systematic reviews of PEPs, studies examining trends related to PEPs, and metaanalyses of PEPs. Various studies have examined trends related to parenting education [14-17]. However, systematic review or meta-analysis studies focused on the development and implementation of education programs for refugees and migrants such as North Korean defectors are still insufficient. Thus, this study aimed to review and analyze past studies focused on the development and implementation of PEPs for refugees and migrants in South Korea and abroad.

Refugee and migrant parents are in dire need of not only short-term and government-supported financial aid but also various other support programs to resolve the psychological difficulties and conflicts they face in their new environments [2,3]. Parents should be offered education and training to overcome conflict and maladjustment as they assimilate into society. Moreover, in order to provide practical assistance with parenting, programs should be tailored to the specific environments, conditions, and needs of parents. It is important to examine how past programs were planned and organized to develop optimal parenting education programs. Therefore, it is necessary to specifically compare the effectiveness of existing PEPs in terms of their implementation in order to develop an effective PEP that sufficiently addresses various parenting competence factors and developmental stage-specific factors. This study aimed to systematically review the related literature, analyze the effects of various PEPs, and examine issues related to parenting education for socioeconomically vulnerable refugee and migrant parents, as well as to present data for the development of such programs in the future. The following study questions were developed for this purpose.

\section{Objectives}

The aim of this study was to analyze the effects and effect sizes of PEPs for refugee and migrant parents through a systematic review. The specific objectives and scope of the research were as follows.

- What is the overall magnitude of the effect of parenting education on refugee and migrant parents' parenting efficacy, positive parenting behaviors, parenting stress, and parent-child relationships?

- Which study/environmental variables (i.e., whether the study included both parents or mothers only, the ages of children, the participation of children during the intervention, the number of sessions) had the most influence on the effect sizes of PEPs?

- Which research method-related variables (i.e., research design, publication type) had the most influence on the effect sizes of PEPs?

\section{Definition of Terminology}

\section{1) Refugee and migrant parents}

Refugees are individuals who seek refuge outside of their 
countries of origin due to feared persecution, conflict, violence, or other circumstances that have led to serious disturbances in the public order, and who, as a result, require international protection. The terms "refugee" and "migrant"' are the terms preferred by the United Nations Refugee Agency. This definition allows us to recognize that the rights of all migrating people must be respected and protected and raises public awareness that refugees and asylum-seekers are protected under a special legal system according to their special needs and rights [18]. Therefore, the term "refugee and migrant parents" in this study refers to refugee, migrant, or immigrant parents aged 19 years or older whose socioeconomic status is vulnerable. A vulnerable social and economic status refers to the various disadvantages an individual faces under the same social and economic conditions as individuals who were born and educated in the country in which the vulnerable person resides due to the difficulty of adapting to a new society and insufficient education. Such individuals require support through government policies and programs.

\section{2) Parenting education programs}

In this study, PEPs refer to parenting education interventions for refugee and migrant parents that offer education, information, or lectures by experts as well as counseling, training, and mentoring.

\section{METHODS}

Ethics statement: This study is a literature review of previously published studies and was therefore exempt from institutional review board approval.

\section{Research Design}

A systematic literature review and meta-analysis of studies were conducted to collect and analyze the results of studies on the effects of PEPs on the parenting attitudes of refugee and migrant parents.

\section{Key Questions}

The specific questions and population, intervention, comparison, outcome, and study design (PICO-SD) framework for the systematic literature review are described below. In this study, the participants and interventions were refugee parents and PEPs, respectively.

This study was conducted in accordance with the systematic review handbook of the Cochrane Collaboration guidelines on systematic review reports, proposed by the Preferred
Reporting Items for Systematic Reviews and Meta-Analyses (PRISMA) group. After selecting the key questions, terms corresponding to the PICO-SD items for the literature on PEPs were searched using international and South Korean electronic databases of scholarly articles and identified according to the inclusion and exclusion criteria.

\section{Selection Criteria}

\section{1) Participants}

The participants of this study were refugee and migrant parents over the age of 19 with vulnerable socioeconomic conditions. "Refugee", "transients and migrants", "emigrants and immigrants", "asylum seeker", and "displaced person" were used as search terms for refugees, and both Medical Subject Headings (MeSH) and EMBASE Tree (EMTREE) on refugees were included. For international databases, the main key words used for the search were: ("refugees" [MeSH] OR "emigrants" OR "immigrants") OR ("emigration and immigration" [MeSH]). For Korean databases, the main keywords used to identify the participants were: ("North Korea defection" OR "North Korea refugees" OR "migrants" OR "refugees").

\section{2) Intervention}

PEPs for refugee parents were searched in this study. Keywords used for the literature search included "parenting" [MeSH, Cochrane], "child rearing" [MeSH, Cochrane], "education" [MeSH, Cochrane], "parent-child relations" [MeSH], "mother-child relations" [MeSH], "father-child relations" [MeSH], "object attachment" [MeSH], "parent-infant bonding" [CINAHL], and "parents/education" [MeSH]. PEPs conducted using education or information, counseling or psychotherapy, and behavioral therapy were included. For Korean databases, the terms used to search for interventions were: ("parenting" OR "nurturing" OR "parenting education" OR "parenting education program*" OR "parent-child*" OR "parent-children*" OR "mother-child*" OR "attachment*").

\section{3) Comparisons}

Studies were selected if the comparison groups received only handbooks or information rather than direct parenting education or interventions.

\section{4) Outcomes}

Studies with self-reported or measured quantitative values for pre- and post-outcome variables, including parenting efficacy, positive parenting behaviors, parenting stress, and parent-child relationships following refugee parents' attendance of a PEP, were selected. 


\section{5) Types of studies}

Randomized controlled trials (RCTs), quasi-experimental studies (non-equivalent control group design), and a group of pretest-posttest studies were selected.

\section{Exclusion Criteria}

The exclusion criteria for the data analysis were as follows: 1) studies of parents in general, parents of adolescents, and parents of children with specific health problems such as physical and mental disabilities; 2) studies that examined families that were not socioeconomically vulnerable; 3) studies with outcome variables other than parenting efficacy, parenting stress, parent-child relationships, or parenting behaviors; 4) studies that only proposed protocols for parenting education; 5) qualitative studies such as case studies, descriptive studies using interviews, descriptive quantitative studies, meta-analyses, review articles, and animal studies; and 6) repeat studies.

\section{Literature Search and Selection}

\section{1) Literature search}

A data search was conducted for all published studies related to parenting education for refugee and migrant parents from March 1 to August 10, 2020. This study aimed to systematically review and meta-analyze the effects of PEPs for refugee and migrant parents published from 2000 to 2020. This not only marks a period of time during which the number of North Korean defectors who entered South Korea sharply increased, but also when the legal status of other refugees began to be recognized [19]. The international databases that were searched included PubMed, Excerpta Medica database (EMBASE), Cumulative Index to Nursing and Allied Health Literature (CINAHL), and the Cochrane Register Controlled Trials (CENTRAL). The Korean databases that were searched in this study were the Korean Medical database (KMbase), and Research Information Sharing Service (RISS). Additionally, after conducting an online search of these databases, the lists of references were searched manually. MeSH terms and the texts of the titles and abstracts were searched using AND/OR in a truncated search to determine the search formula. Only studies published in English or Korean were included. There were no limitations with regard to the study period when searching for all published studies.

\section{2) Data collection}

This study was conducted in accordance with PRISMA guidelines for systematic literature reviews, and a flow chart was used to illustrate the step-by-step article selection process
(Figure 1). Throughout the data collection process and the selection of articles, every study included in the analysis was independently reviewed by two researchers. Regular meetings were held to cross-review the selected studies. If there was disagreement between the two researchers, the study was reviewed against the selection and exclusion criteria until a consensus was reached. First, a list was created for studies discovered through the databases, and any repeat studies were excluded using the bibliographic export program EndNote X9. After repeat articles were excluded, the titles and abstracts of the remaining articles were reviewed to confirm that they satisfied the selection criteria. When it was difficult to determine whether a study satisfied the selection criteria through the title or abstract, the full text was examined to further assess whether the article was relevant. Bibliographic information for all of the studies was handled identically, and records were kept to document the step-by-step process of selecting the studies.

\section{3) Quality assessment of the literature}

The quality of the final selected studies was independently assessed by two researchers using the Cochrane's Risk of Bias tool (ROB) and the Risk of Bias Assessment Tool for NonRandomized Studies (RoBANS), and disagreements were resolved by reviewing the articles together until an agreement was reached and a conclusion could be drawn. The ROB consists of seven items on random sequence generation, allocation concealment, blinding of participants and personnel, blinding of the assessment of outcomes, incomplete outcome data, selective reporting, and other biases to assess the quality of RCTs, and the level of bias risk for each item is classified as "low risk", "high risk", or "unclear" (Supplement 1). The RoBANS tool is used to assess the risk of bias in non-randomized studies, including quasi-experimental research studies and single-group experimental studies with 6 items on participant selection, confounding variables, intervention (exposure) measurements, blinding of the assessment of outcomes, incomplete outcome data, and selective outcome reporting (Supplement 2). Each item was independently evaluated by the researchers, and studies for which a quality evaluation was conducted underwent a final evaluation through discussion.

\section{4) Data extraction}

The researchers extracted and recorded the following information in the coding table for the final studies that were included in the systematic literature review and meta-analysis: author, publication year, publishing country (language), effect size, study design, sample size, outcome variable, number of intervention sessions, the ages of children, child participation, publication type, and participants. 


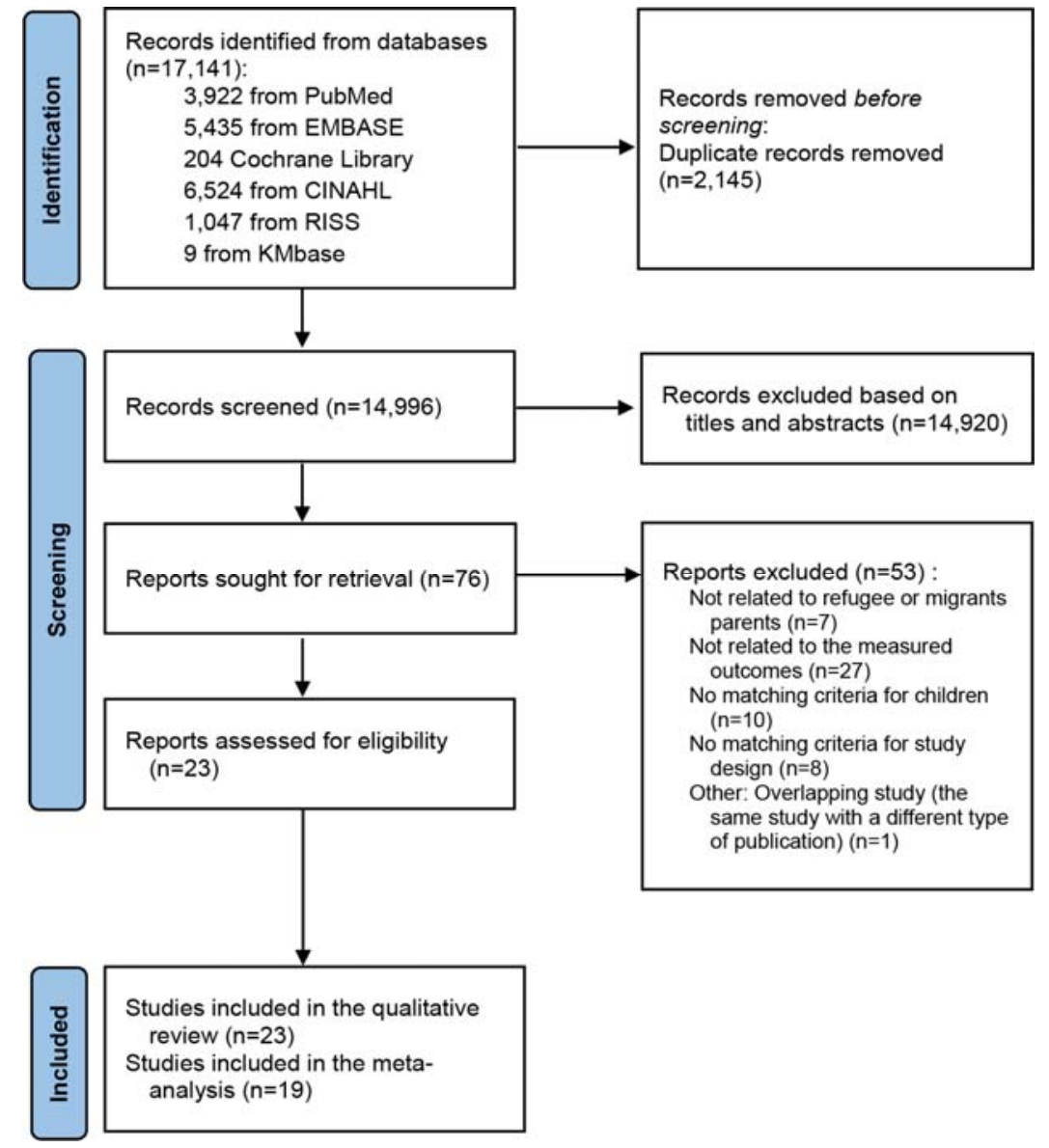

Figure 1. Flow diagram of study selection.

\section{Data Analysis}

When examining the outcome variables of the studies in the final quality assessment, the positive variables included parenting behaviors, parenting efficacy, and parent-child relationships, and the negative variables included parenting stress. In the meta-analysis, the researchers excluded studies that did not include the statistics required for analysis and studies that only included the subscale scores of the outcome variables. Among the factors of parenting behaviors, the effect size was calculated only for positive parenting behaviors. When two different tools were used to measure one outcome variable in a study, the statistics measured by the tool that was more frequently used in other studies were included in the analysis. Moreover, only post-hoc scores measured at the end of the intervention were used to assess the direct effects of PEPs.

\section{1) Comprehensive Meta-Analysis 3.0 program}

The Comprehensive Meta-Analysis 3.0 program (Biostat, Inc., Englewood, NJ, USA) was used for a statistical analysis of the effect size and homogeneity of PEPs. First, the stand- ardized mean difference (SMD) was used to calculate the effect size of the outcome values. The SMD is a summary statistic to standardize the result values of the same outcome variable measured by different tools in different studies. A random-effect model was used to calculate the SMD since the samples, intervention methods, intervention periods, and measurement tools varied across different studies. The effect sizes of the subgroups according to intervention type were calculated only when there were more than four studies. A forest plot was used to assess the direction of the effect values of the individual studies selected for analysis and to determine whether the confidence intervals (CIs) between the studies overlapped.

\section{2) Interpretation of the effect sizes and the $x 2$ null hypothesis test}

In this study, the effect sizes were interpreted according to Cohen's criteria [20]. An effect size of less than .20 was considered very small, $0.20-0.50$ was considered small, $0.50-0.80$ was considered medium, $0.80-1.00$ was considered large, and 1.00 or greater was considered very large. 
The $x 2$ null hypothesis test was conducted to assess the statistical heterogeneity of the effect size, and significant heterogeneity was confirmed after conducting the Higgins $\mathrm{I}^{2}$ test. $\mathrm{I}^{2}$ values of $0.0 \%, 50.0 \%$, and $75.0 \%$ indicated no, moderate, and high heterogeneity, respectively.

\section{3) Reliability test for publication bias and effect size}

Publication bias of the articles identified in the search was tested by creating a funnel plot and performing the Egger linear regression asymmetry test.

\section{RESULTS}

\section{Data Selection}

The first literature search was conducted of PubMed $(n=$ 3,922), Embase ( $n=5,435)$, Cochrane Library $(n=204)$, CINAHL $(n=6,524)$, RISS $(n=1,047)$, and KMbase $(n=9)$. A total of 14,996 articles were searched after excluding 2,145 repeat studies. The titles and abstracts of the articles were reviewed based on the selection and exclusion criteria. Consequently, 14,920 studies were excluded. The original texts of the remaining 76 studies were reviewed, and 53 were excluded that did not satisfy the selection criteria for participant selection or research design or were repeat studies. The remaining 23 studies were selected, and the 19 studies that could be quantitatively reviewed were ultimately used in the meta-analysis (Figure 1).

\section{Quality Assessment}

The quality appraisal results of the 23 studies are shown in Supplement 1 and Supplement 2. Of the 10 RCTs, random sequence generation and allocation concealment were identified in all of the studies $(100.0 \%)$, blinding of the participants and researchers was identified in 8 studies (80.0\%), incomplete outcome data were identified in seven studies $(70.0 \%)$, and selective reporting was identified in nine studies (90.0\%). These studies were considered to have a low risk of bias in the corresponding areas. However, seven studies (70.0\%) were considered to have a high risk of bias related to blinding of the assessment of outcomes. Three studies (30.0\%) were considered to have a high risk of bias for other reasons that threatened their validity. The risk of bias was the lowest from random sequence generation and allocation concealment, which suggests that most of the included studies had a low selection bias. The highest risk of bias was related to blinding of the outcome assessment and other reasons. The substantial risk of bias in these categories may have been a result of some studies' use of self-report data or some studies' use of in- adequate disclosure of the use of a manual or expertise of the person administering the intervention (Supplement 1). The risk of bias in non-randomized studies, such as quasi-experimental studies or one-group experimental studies, was assessed using the RoBANS tool. Of the 13 studies, the risk of bias was high for participant selection in 11 studies (84.6\%), intervention (exposure) measurements in 11 studies (84.6\%), and confounding variables in eight studies (61.5\%). These biases were likely due to the nature of quasi-experimental studies in which participants are selected based on research convenience and the failure to address confounding variables. The blinding of the assessment of outcomes in 10 studies (76.9\%), incomplete data in nine studies (69.2\%), and selective outcome reporting in 10 studies $(76.9 \%)$ showed a relatively low risk of bias (Supplement 2).

\section{General Characteristics of Studies Included in the Meta-analysis}

The general characteristics of the 19 studies on PEPs included in the meta-analysis were individually analyzed and are listed in Table 1. Two studies were published in or before 2010 (10.6\%), seven studies were published from 2011 to 2015 $(36.8 \%)$, and 10 studies were published from 2016 to 2020 (52.6\%). Five studies (26.3\%) were conducted in Korea, and 14 studies $(73.7 \%)$ were conducted in other countries. Of the 19 total studies, four were about refugees $(21.1 \%)$, while 15 were about migrants $(78.9 \%)$. The PEPs included in the studies were generally mixed interventions. With the exception of one Korean study that only used lectures (5.3\%), the studies mostly used lectures, role-play, counseling, and group activities. Eleven studies (57.9\%) included only mothers, while eight studies $(42.1 \%)$ included both parents. Five studies (26.3\%) included child participation in the program. Six studies $(31.6 \%)$ included children under 7 years of age, nine studies $(47.4 \%)$ included children aged 8 to 14 years, and four studies $(21.0 \%)$ included children of any age. The least common number of sessions was 19 or more $(n=3,15.8 \%)$, followed by 9 to $18(n=6,31.6 \%)$ and 5 to $8(n=10,52.6 \%)$. Eight studies $(42.1 \%)$ measured parenting efficacy as the outcome variable of parenting education. Positive parenting behaviors and parent-child relationships were examined in 5 studies $(26.3 \%)$, and parenting stress was examined in 11 studies (57.9\%) (duplicate measurements).

\section{Effect Sizes of Parenting Education Programs}

1) Overall effects of parenting education programs and the effect sizes of outcome measures

In this study, the effect sizes of 29 outcome variables from 
Table 1. Characteristics of Studies Included in the Analysis $(N=19)$

\begin{tabular}{|c|c|c|c|c|c|c|c|c|c|c|}
\hline $\begin{array}{l}\text { First author } \\
\text { (year) [R] }\end{array}$ & Country & $\begin{array}{l}\text { Effect } \\
\text { size }\end{array}$ & $\begin{array}{l}\text { Research } \\
\text { design }\end{array}$ & $\begin{array}{l}\text { Sample size } \\
\text { Exp./Cont. }\end{array}$ & Outcome & Sessions & $\begin{array}{l}\text { Child } \\
\text { age } \\
\text { (year) }\end{array}$ & $\begin{array}{c}\text { Child } \\
\text { participation }\end{array}$ & $\begin{array}{l}\text { Publication } \\
\text { type }\end{array}$ & Participants \\
\hline $\begin{array}{c}\text { Bjørknes } \\
(2013)[21]\end{array}$ & $\begin{array}{l}\text { Norway } \\
\text { (English) }\end{array}$ & 0.56 & RCT & $50 / 46$ & $\mathrm{PP}$ & 18 & $3-9$ & No & $\begin{array}{l}\text { Academic } \\
\text { article }\end{array}$ & $\begin{array}{l}\text { Mothers } \\
\text { (migrants) }\end{array}$ \\
\hline $\begin{array}{c}\text { Choe } \\
(2010)[22]\end{array}$ & $\begin{array}{c}\text { Republic of } \\
\text { Korea } \\
\text { (Korean) }\end{array}$ & 1.56 & $\begin{array}{c}\text { Quasi- } \\
\text { experimental }\end{array}$ & $7 / 7$ & PE & 8 & $2-10$ & No & $\begin{array}{l}\text { Academic } \\
\text { article }\end{array}$ & $\begin{array}{l}\text { Mothers } \\
\text { (migrants) }\end{array}$ \\
\hline $\begin{array}{c}\text { Chung } \\
(2015)[23]\end{array}$ & $\begin{array}{l}\text { Hong Kong } \\
\text { (English) }\end{array}$ & 0.02 & $\mathrm{RCT}$ & $30 / 30 / 31^{\dagger}$ & PS & 8 & $3-6$ & No & $\begin{array}{l}\text { Academic } \\
\text { article }\end{array}$ & $\begin{array}{l}\text { Parents } \\
\text { (migrants) }\end{array}$ \\
\hline $\begin{array}{c}\text { Garcia- } \\
\text { Huidobro } \\
(2019)[24]\end{array}$ & $\begin{array}{c}\text { USA } \\
\text { (English) }\end{array}$ & 0.16 & One-group & 23 & PR & 8 & $10-14$ & Yes & $\begin{array}{l}\text { Academic } \\
\text { article }\end{array}$ & $\begin{array}{l}\text { Parents } \\
\text { (migrants) }\end{array}$ \\
\hline $\begin{array}{l}\text { Jeong } \\
(2006)[6]\end{array}$ & $\begin{array}{c}\text { Republic of } \\
\text { Korea } \\
\text { (Korean) }\end{array}$ & 1.97 & One-group & 5 & PS & 5 & $9-14$ & Yes & Thesis & $\begin{array}{c}\text { Mothers } \\
\text { (North Korean } \\
\text { defectors) }\end{array}$ \\
\hline $\begin{array}{c}\text { Chung } \\
(2013)[25]\end{array}$ & $\begin{array}{c}\text { Republic of } \\
\text { Korea } \\
\text { (Korean) }\end{array}$ & 1.86 & $\begin{array}{l}\text { Quasi- } \\
\text { experimental }\end{array}$ & $8 / 8$ & PS & 8 & $1-14$ & No & $\begin{array}{c}\text { Academic } \\
\text { article }\end{array}$ & $\begin{array}{l}\text { Mothers } \\
\text { (migrants) }\end{array}$ \\
\hline$\underset{\text { (2016) [26] }}{\text { Kim }}$ & $\begin{array}{l}\text { China } \\
\text { (Korean) }\end{array}$ & 1.34 & $\begin{array}{c}\text { Quasi- } \\
\text { experimental }\end{array}$ & $12 / 12$ & PS & 7 & $8-12$ & No & Thesis & $\begin{array}{l}\text { Mothers } \\
\text { (migrants) }\end{array}$ \\
\hline$\underset{\text { (2014) [27] }}{\text { Kim }}$ & $\begin{array}{c}\text { Republic of } \\
\text { Korea } \\
\text { (Korean) }\end{array}$ & 0.73 & $\begin{array}{c}\text { Quasi- } \\
\text { experimental }\end{array}$ & $23 / 27$ & PS & 6 & $3-6$ & No & $\begin{array}{l}\text { Academic } \\
\text { article }\end{array}$ & $\begin{array}{l}\text { Mother } \\
\text { (migrants) }\end{array}$ \\
\hline$\underset{(2012)[28]}{\text { Kim }}$ & $\begin{array}{c}\text { Republic of } \\
\text { Korea } \\
\text { (Korean) }\end{array}$ & 0.43 & One-group & 4 & PE & 8 & $9-17$ & No & Thesis & $\begin{array}{l}\text { Mothers } \\
\text { (migrants) }\end{array}$ \\
\hline $\begin{array}{c}\text { Lakkis } \\
(2020) \text { [29] }\end{array}$ & $\begin{array}{c}\text { Lebanon, Jordan } \\
\text { Syria (English) }\end{array}$ & 1.25 & One-group & 125 & PS & 21 & $3-6$ & No & $\begin{array}{l}\text { Academic } \\
\text { article }\end{array}$ & $\begin{array}{l}\text { Parents } \\
\text { (refugee) }\end{array}$ \\
\hline $\begin{array}{c}\text { Lau } \\
(2011) \text { [30] }\end{array}$ & $\begin{array}{c}\text { USA } \\
\text { (English) }\end{array}$ & 0.04 & $\begin{array}{c}\text { Quasi- } \\
\text { experimental }\end{array}$ & $32 / 22$ & PS & 14 & $5-12$ & No & $\begin{array}{l}\text { Academic } \\
\text { article }\end{array}$ & $\begin{array}{l}\text { Parents } \\
\text { (migrants) }\end{array}$ \\
\hline $\begin{array}{c}\text { Lee } \\
(2017) \text { [31] }\end{array}$ & $\begin{array}{l}\text { Hong Kong } \\
\text { (English) }\end{array}$ & 0.09 & $\begin{array}{c}\text { Quasi- } \\
\text { experimental }\end{array}$ & $11 / 15$ & PS & 16 & $5-12$ & No & $\begin{array}{l}\text { Academic } \\
\text { article }\end{array}$ & $\begin{array}{l}\text { Mothers } \\
\text { (Chinese } \\
\text { migrant) }\end{array}$ \\
\hline $\begin{array}{c}\text { Leung } \\
\text { (2011) [32] }\end{array}$ & $\begin{array}{l}\text { Hong Kong } \\
\text { (English) }\end{array}$ & 0.24 & $\mathrm{RCT}$ & $66 / 54$ & PS & 30 & $3-5$ & Yes & $\begin{array}{l}\text { Academic } \\
\text { article }\end{array}$ & $\begin{array}{l}\text { Parents } \\
\text { (Chinese } \\
\text { migrants) }\end{array}$ \\
\hline $\begin{array}{c}\text { Miller } \\
(2020)[33]\end{array}$ & $\begin{array}{l}\text { Lebanon } \\
\text { (English) }\end{array}$ & 0.51 & RCT & $78 / 73$ & PS & 9 & $7-12$ & No & $\begin{array}{l}\text { Academic } \\
\text { article }\end{array}$ & $\begin{array}{l}\text { Parents } \\
\text { (refugees) }\end{array}$ \\
\hline $\begin{array}{c}\text { Osman } \\
(2017)[34]\end{array}$ & $\begin{array}{l}\text { Sweden } \\
\text { (English) }\end{array}$ & 2.00 & RCT & $60 / 60$ & PE & 12 & $11-16$ & No & $\begin{array}{l}\text { Academic } \\
\text { article }\end{array}$ & $\begin{array}{c}\text { Parents } \\
\text { (migrants) }\end{array}$ \\
\hline $\begin{array}{l}\text { Ponguta } \\
(2020)[35]\end{array}$ & $\begin{array}{l}\text { Lebanon } \\
\text { (English) }\end{array}$ & 0.78 & RCT & $53 / 53$ & PS & 25 & $2-7$ & Yes & $\begin{array}{c}\text { Academic } \\
\text { article }\end{array}$ & $\begin{array}{l}\text { Mothers } \\
\text { (refugee) }\end{array}$ \\
\hline $\begin{array}{c}\text { Puffer } \\
\text { (2017) [36] }\end{array}$ & $\begin{array}{l}\text { Thailand } \\
\text { (English) }\end{array}$ & 0.40 & $\mathrm{RCT}$ & $239 / 240$ & PR & 12 & $8-12$ & Yes & $\begin{array}{l}\text { Academic } \\
\text { article }\end{array}$ & $\begin{array}{l}\text { Parents } \\
\text { (migrants) }\end{array}$ \\
\hline $\begin{array}{c}\text { Shon } \\
\text { (2019) [37] }\end{array}$ & $\begin{array}{c}\text { Kyrgyzstan } \\
\text { (Korean) }\end{array}$ & 2.48 & $\begin{array}{c}\text { Quasi- } \\
\text { experimental }\end{array}$ & $25 / 26 / 25^{*}$ & PE & 8 & $6 m-3$ & No & Thesis & $\begin{array}{l}\text { Mothers } \\
\text { (migrants) }\end{array}$ \\
\hline $\begin{array}{c}\text { Shon } \\
\text { (2019) [38] }\end{array}$ & $\begin{array}{l}\text { China } \\
\text { (English) }\end{array}$ & 0.06 & $\mathrm{RCT}$ & $28 / 26$ & PE & 6 & $\leq 12$ & No & $\begin{array}{c}\text { Academic } \\
\text { article }\end{array}$ & $\begin{array}{l}\text { Mothers } \\
\text { (migrants) }\end{array}$ \\
\hline
\end{tabular}

*Intervention group 1, two comparison group (same area, remote area); ${ }^{\dagger}$ Main intervention group/provided booklets, discussion group/waitlist control group; Cont., control group; Exp., experimental group; PE, parenting efficacy; PP, positive parenting; PR, parent-child relationship; PS, parenting stress; $[\mathrm{R}]$, reference number; RCT, randomized controlled trial. 
the 19 studies included in the meta-analysis were measured. The overall effect size of PEPs for refugee and migrant parents on the outcome variables was medium at 0.75 (95\% CI: 0.52-0.98). Eight studies were used to calculate the effect size of PEPs on parenting efficacy, a positive outcome variable, and the effect size was large at 1.40 (95\% CI: 1.14-1.66), with statistical significance $(z=10.60, p<.001)$. Five studies were used to calculate the effect size of PEPs on positive parenting behaviors, and the effect size was medium at 0.51 (95\% CI: $0.30-0.73)$, also with statistical significance $(z=4.64, p<.001)$. Five studies were used to calculate the effect size of PEPs on parent-child relationships, and the effect size was small at 0.38 (95\% CI: 0.22-0.53), with statistical significance $(z=4.81, p<$ .001). There was substantial heterogeneity for the effect size of PEPs on parenting efficacy $\left(\tau^{2}=0.88, \mathrm{Q}=46.00, \mathrm{df}=7, p<.001\right.$, $\mathrm{I}^{2}=84.78 \%$ ), moderate heterogeneity for the effect size of PEPs on positive parenting behaviors $\left(\tau^{2}=0.07, \mathrm{Q}=7.69, \mathrm{df}=4\right.$, $p=.103, \mathrm{I}^{2}=48.01 \%$ ), and low heterogeneity for the effect size of PEPs on parent-child relationships $\left(\tau^{2}=0.00, \mathrm{Q}=2.16, \mathrm{df}=4\right.$, $\left.p=.071, \mathrm{I}^{2}=0.00 \%\right)$.

Eleven studies were used to calculate the effect size of PEPs on parenting stress, a negative outcome measure, and the overall effect size was medium at 0.64 (95\% CI: 0.50-0.79), which was statistically significant $(\mathrm{z}=8.62, p<.001)$. There was substantial heterogeneity of the effect size $\left(\tau^{2}=0.20, Q=41.28\right.$, $\left.p<.001, \mathrm{I}^{2}=75.78 \%\right)$. In addition, statistically significant differences were found in the effect sizes of the four outcome variables $(\mathrm{Q}=45.71, \mathrm{df}=3, p<.001)$ (Figure 2).

\section{2) Analysis of moderating effects}

The effect sizes were compared using meta-analysis of variance, and the type of participants (mothers only/both parents), age of children, participation of children, numbers of sessions, study design, participant groups, and type of publication (i.e., academic article or thesis) were used as moderators (Table 2). The effect size according to the participant type was statistically significant $(\mathrm{Q}=5.71, p=.017)$, with a difference of 0.93 for PEPs in which only mothers participated and 0.56 for PEPs in which both parents participated. The effect size according to the ages of children was statistically significant $(\mathrm{Q}=21.08, p<.001)$, with a difference of 0.91 for children under 7 years of age, 0.56 for children aged 8 to 14 years, and 0.32 for children of any age (infant to adolescent). The effect size of child participation was statistically significant $(\mathrm{Q}=14.78, p<.001)$, with a difference of 0.41 for participation and 0.77 for non-participation. The effect size according to the number of sessions was also statistically significant $(\mathrm{Q}=6.85$, $p=.032$ ), with a difference of 0.72 for PEPs lasting 5 to 8 sessions, 0.52 for PEPs lasting 9 to 18 sessions, and 0.80 for PEPs that continued for 19 or more sessions. The effect size ac- cording to the research design was statistically significant $(Q=12.35, p=.002)$, with a difference of 0.85 for studies with a one-group pretest-posttest design, 0.86 for quasi-experimental studies, and 0.51 for RCTs.

\section{Risk of Bias Testing and Reliability Testing for Calcu- lated Effect Sizes}

Since the distribution of the calculated effect sizes was asymmetrical, Egger regression analysis was performed to statistically examine the possibility of publication bias. Based on the results $(t=1.45, p=.158)$, we accepted the hypothesis that there was no bias. However, since a definitive conclusion cannot be drawn solely based on these results, we used the trim-and-fill method to create a symmetrical funnel plot if publication bias was suspected. As shown in Figure 3, removing the three newly added studies created an asymmetrical plot (i.e., there were no studies on the left side of the average, especially studies with low effect or sample sizes). This was corrected using the trim-and-fill method. With three modifications, the effect size changed from 0.75 to 0.59 , and the 95\% CI (0.33-0.85) did not include 0, indicating statistical significance. This suggests that publication bias was present, but when examined against the results of the Egger regression analysis, the bias was found not to significantly affect the study data. In other words, the overall effect was robust (Figure 3).

\section{DISCUSSION}

This study aimed to systematically review and meta-analyze the effects of PEPs for refugee and migrant parents in studies published from 2000 to 2020 . This study presents data that will be valuable for the development of similar PEPs in the future. The results are discussed below.

Our results revealed that PEPs had a medium-to-large effect size in terms of their impact on refugee and migrant parents. The overall effect size was 0.75 , indicating that PEPs for refugee and migrant parents were effective. We cannot compare these results directly with the existing evidence due to a lack of meta-analyses on refugees and migrants. However, the difference in the effect size observed in this study (0.75) compared to that of a previous meta-analysis of multicultural parents in South Korea (1.37) [9] and that of a previous study on Korean parents in general (0.76) [17] may have been caused by differences in the subjects' characteristics, the program composition, the educational intervention methods used, and the study design. Although there were differences in the effect sizes, it was confirmed that PEPs had a positive effect on parents' ability to raise children. Thus, PEPs 
(A)

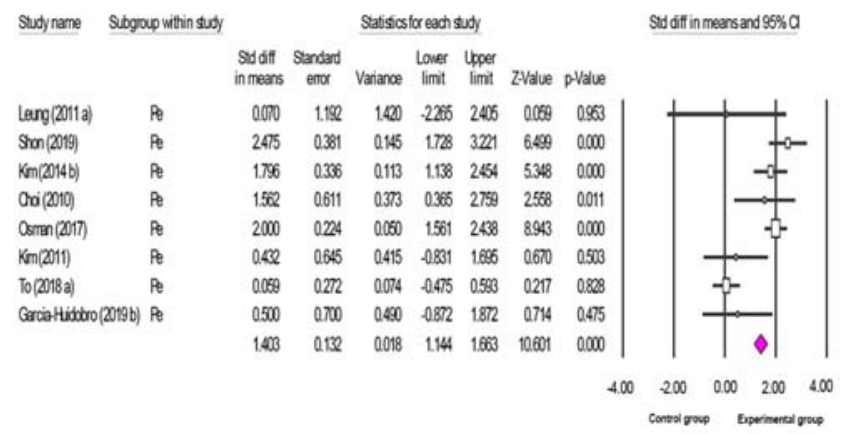

(C)

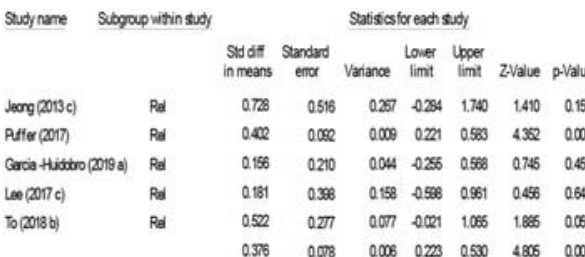

(B)

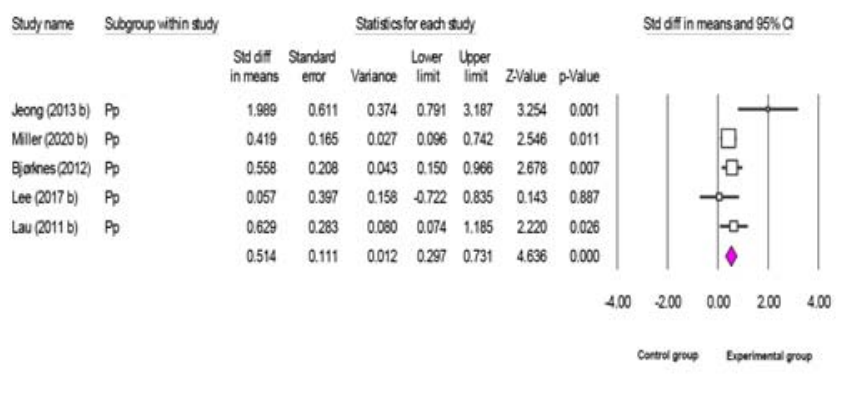

(D)

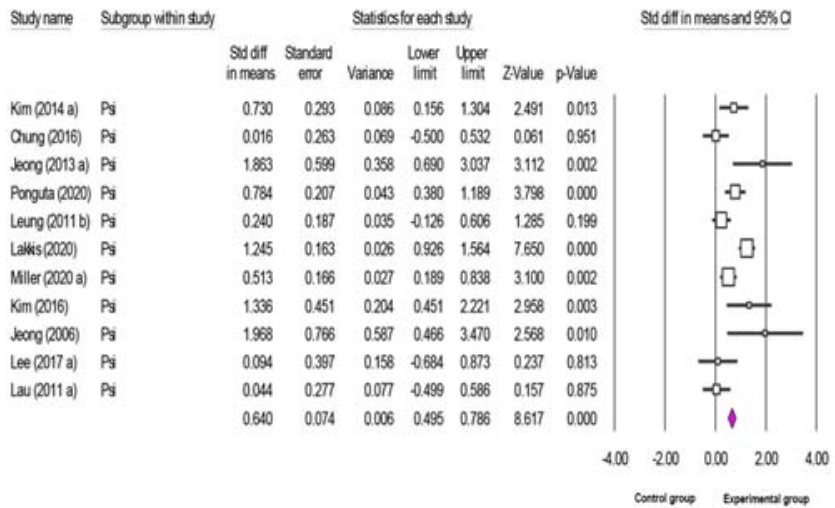

Figure 2. Forest plots of the effects of parenting education program. $\mathrm{ES}=0.75(95 \% \mathrm{Cl}=0.52-0.98), \mathrm{SE}=0.12, x^{2}(\mathrm{Q})=142.84(p<.001)$, $\mathrm{t}^{2}=0.26, \mathrm{I}^{2}=80.40$. (A) Parenting efficacy. Heterogeneity: $\tau^{2}=0.88, x^{2}(\mathrm{Q})=46.00, \mathrm{df}=7(p<.001), \mathrm{I}^{2}=84.78 \%$; test for overall effect: $\mathrm{z}=10.60(p<.001)$. (B) Positive parenting behaviors. Heterogeneity: $\tau^{2}=0.07, x^{2}(Q)=7.69, \mathrm{df}=4(p=.103), \mathrm{I}^{2}=48.01 \%$; test for overall effect: $z=4.64\left(p<\right.$.001). (C) Parent-child relationships. Heterogeneity: $\tau^{2}=0.00, x^{2}(Q)=2.16, d f=4(p=.707), I^{2}=0.0 \%$; test for overall effect: $z=4.81(p<.001)$. (D) Parenting stress. Heterogeneity: $\tau^{2}=0.20, x^{2}(Q)=41.28, d f=10(p<.001), I^{2}=75.8 \%$; test for overall effect: $z=8.62(p<.001)$. Cl, confidence interval; ES, effect size; Pe, parenting efficacy; Pp, positive parenting; Psi, parenting stress index; Rel, parent-child relation; SE, standard error; Std diff, standardized mean difference.

should be used to help refugee and migrant parents raise their children well.

North Korean refugees and migrant parents must undergo the process of adapting to an unfamiliar society in which the social norms and customs are largely different. During the adaptation process, these parents experience significant changes that can cause confusion about gender roles and intergenerational relationships between family members [13]. The unfamiliar social norms and customs of the societies to which families have migrated or fled may differ greatly from those of the societies from which they came. Problems related to adjustment that occur at this time are likely to affect the relationships between parents and children [39]. The acculturation process creates serious psychological stress for parents who migrate as adults since they have already experienced full socialization in their home country. However, children are typically able to adjust to the new society quicker than their parents, resulting in a gap in the adjustment level of parents and children [40]. Kim et al.[41] found that highly accul- turated Korean immigrant mothers living in the United States tended to discipline their children appropriately, and the degree to which mothers harshly disciplined their children decreased after poorly acculturated mothers received parenting education. During the 1-year follow-up, mothers in the intervention group were found to have maintained the significant effect of parenting education on positive discipline, and mothers in the intervention group reported decreased problem behaviors and increased social competence in their children. Parents who had not sufficiently adapted to a new society may have needed more time and practice to integrate unfamiliar parenting strategies into their existing parenting practices. Depression has been reported not only among immigrant parents but also among adolescents due to intergenerational acculturation conflicts [3]. The acculturation gap has been found to positively relate to internalization and externalization by adolescent children [42]. In particular, expressions of affection, parental control practices, discipline, expectations held by parents such as academic achievement 
Table 2. Effect Sizes by Subgroup and Total Effect Size Related to General Characteristics, Program Characteristics, and Research Methods $\left(N^{*}=29\right)$

\begin{tabular}{|c|c|c|c|c|c|c|c|}
\hline Variables & Categories & $\mathrm{k}$ & ES & $95 \% \mathrm{CI}$ & SE & Q & $p$ \\
\hline \multirow{4}{*}{$\begin{array}{l}\text { Major outcome } \\
\text { variables }\end{array}$} & Parenting efficacy & 8 & 1.40 & $1.14-1.66$ & 0.13 & \multirow[t]{4}{*}{45.71} & \multirow[t]{4}{*}{$<.001$} \\
\hline & Positive parenting behaviors & 5 & 0.51 & $0.30-0.73$ & 0.11 & & \\
\hline & Parenting stress & 11 & 0.64 & $0.50-0.79$ & 0.07 & & \\
\hline & Parent-child relationships & 5 & 0.38 & $0.22-0.53$ & 0.08 & & \\
\hline \multirow[t]{2}{*}{ Group } & Refugees & 5 & 0.76 & $0.59-0.92$ & 0.09 & \multirow[t]{2}{*}{3.49} & \multirow[t]{2}{*}{.062} \\
\hline & Migrants & 24 & 0.57 & $0.46-0.67$ & 0.05 & & \\
\hline \multirow[t]{2}{*}{ Participants } & Only mothers & 17 & 0.93 & $0.58-1.27$ & 0.18 & \multirow[t]{2}{*}{5.71} & \multirow[t]{2}{*}{.017} \\
\hline & Both parents & 12 & 0.56 & $0.24-0.88$ & 1.16 & & \\
\hline \multirow{3}{*}{ Child age (year) } & $\leq 7$ & 12 & 0.91 & $0.75-1.07$ & 0.08 & \multirow[t]{3}{*}{21.08} & \multirow{3}{*}{$<.001$} \\
\hline & $8-14$ & 9 & 0.56 & $0.43-0.69$ & 0.06 & & \\
\hline & All ages & 8 & 0.32 & $0.13-0.53$ & 0.10 & & \\
\hline \multirow[t]{2}{*}{ Child participation } & Yes & 7 & 0.41 & $0.27-0.55$ & 0.07 & \multirow[t]{2}{*}{14.78} & \multirow[t]{2}{*}{$<.001$} \\
\hline & No & 22 & 0.77 & $0.65-0.88$ & 0.06 & & \\
\hline \multirow[t]{3}{*}{ Sessions } & $5-8$ & 15 & 0.72 & $0.54-0.91$ & 0.09 & \multirow[t]{3}{*}{6.85} & \multirow[t]{3}{*}{.032} \\
\hline & $9-18$ & 10 & 0.52 & $0.40-0.64$ & 0.00 & & \\
\hline & $\geq 19$ & 4 & 0.80 & $0.59-1.00$ & 0.01 & & \\
\hline \multirow[t]{3}{*}{ Research design } & One group pretest-posttest & 4 & 0.85 & $0.61-1.10$ & 0.12 & \multirow[t]{3}{*}{12.35} & \multirow[t]{3}{*}{.002} \\
\hline & Quasi-experimental & 13 & 0.86 & $0.65-1.07$ & 0.11 & & \\
\hline & $\mathrm{RCT}$ & 12 & 0.51 & $0.40-0.62$ & 0.06 & & \\
\hline \multirow[t]{2}{*}{ Publication type } & Academic article & 20 & 0.61 & $0.51-0.72$ & 0.05 & \multirow[t]{2}{*}{0.07} & \multirow[t]{2}{*}{.796} \\
\hline & Thesis & 9 & 0.64 & $0.48-0.80$ & 0.08 & & \\
\hline
\end{tabular}

*29 effect sizes extracted from 19 studies; CI, confidence interval; ES, effect size; RCT, randomized controlled trial; SE, standard error.

[43], and child-rearing strategies [44] have all been found to differ for children who have migrated to a new country when compared to life in their countries of origin. In addition, misunderstandings between parents and children may develop due to differences in the pace of language and cultural acquisition that lead to inefficient communication and negatively affect parent-child relationships [42]. Regular parent-child conflict and parenting stress have a detrimental impact on the adjustment of refugee and migrant families. As a result of the meta-analysis in the present study, PEPs were found to be highly effective for improving parenting efficacy, with an effect size of 1.40, and moderately effective for improving positive parenting behaviors (0.51) and parenting stress (0.64). This supports previous findings that PEPs had positive effects on parenting efficacy and parenting attitudes [11,12]. As such, it can be inferred that, as refugees or migrant parents adjust to a new environment, the psychological burden of raising children can be mitigated by the effects of educational interventions, which support the development of positive parenting attitudes. In addition, PEPs improve refugee and migrant parents' confidence related to raising children. Therefore, providing parenting-related information on parenting styles and educational systems through individual or group sessions and establishing parenting support systems through social networks for refugee and migrant parents in a new society provides them with emotional support, increases their confidence related to parenting, reduces their parenting stress, and fosters their parenting competence. Such programs would ultimately facilitate stable and successful settlement in their new communities.

Educational interventions were relatively less effective at improving parent-child relationships (0.38), however, which is likely due to the small number of included studies and the use of only parental outcome variables in the synthesis of data to calculate the effect size. Therefore, definitive conclusions cannot be drawn solely based on our findings, and studies with stricter criteria are needed to improve the validity and reliability of our study findings.

We conducted an analysis with moderators that can systematically explain the differences in the effects and heterogeneity of PEPs included in meta-analysis studies. There were statistically significant differences according to the subjects of programs, the ages of children, the participation of child, the number of sessions, and the study design. Although it was not statistically significant, the effect size of PEPs for refugees was 0.76, which was larger than the effect size of PEPs for migrants 
(A)

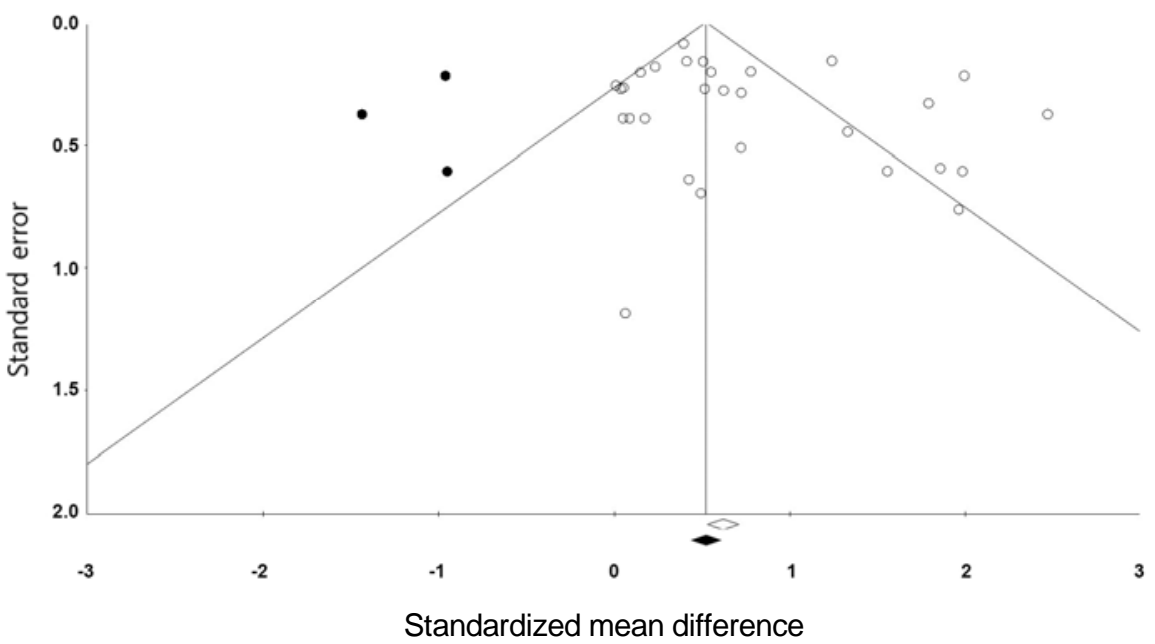

(B)

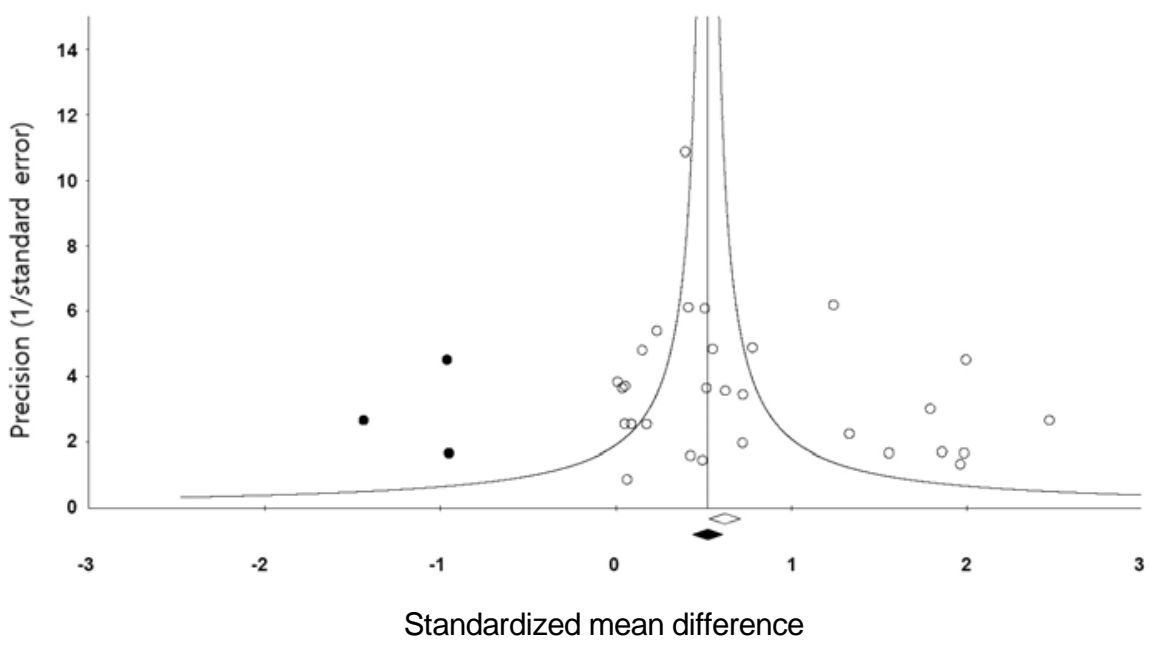

Figure 3. Funnel plot. (A) Funnel plot of standard error by the standardized mean difference. (B) Funnel plot of precision by the standardized mean difference.

(0.57). It is assumed that the small number of studies included in our meta-analysis, the thesis, and the nature of a single-group experimental study influenced the effect size, suggesting a need for repeat studies in the future. The effect sizes of PEPs according to the study participants were significantly larger when only the mother was included than when both parents were included. In a previous study [12], it was reported that the effect size was largest when both parents participated in mixed-parent group programs. Since the results of that study contradict those of this study, it is necessary to repeat studies in the future by looking for inconsistent results. There were statistically significant differences according to children's age and the participation of children in PEPs. The effect size was approximately two times greater when children were not participated in PEPs than when they were participated. This finding, which is similar to that of a previous study [9], is attributable to the fact, although childcare and other activities for children are often provided during PEPs, parents of young children often experience a relatively high degree of anxiety when accepting caregiving assistance from others, which in turn can decrease their concentration during PEPs [45]. In addition, young children cannot resolve or meet their needs on their own and require assistance from parents or caregivers. Therefore, if the participation of children in PEPs is not essential for the education program, including in programs that promote interaction with children or improve parent-child relationships, alternative childcare options should be offered to participants in PEPs. The effect sizes of PEPs according to the ages of children were largest when children were younger than 7 years of age (0.91), followed by children aged 8 to 14 years (0.56) and children of any age (0.31). These results are consistent with the findings of a previous study by Lee et al.[46] that found that PEPs were effective when administered to parents of preschool-aged children. This may 
be because it might be more difficult to change established parenting attitudes or styles among parents of older children compared to parents of younger children. Parents with young children may still be experimenting with various parenting attitudes and styles, and PEPs were more useful for parents of young children with less parenting experience. These results contradict the findings of previous studies that found that programs targeting parents of older children, as opposed to younger children, were more effective $(0.97$ for parents of elementary school children; 0.77 for parents of adolescents; 0.65 for parents of preschool and elementary school children; 0.62 for parents of infants and toddlers) [12,17]. This inconsistency may indicate that the effects of parenting education vary according to the characteristics of the subjects of previous studies and the degree of parents' acculturation to a new society. Thus, repeat studies may be needed.

The effect sizes of PEPs according to the number of sessions was 0.80 for PEPs lasting 19 sessions and above, followed by 0.72 for PEPs lasting 5 to 8 sessions and 0.52 for PEPs lasting 9 to 18 sessions. This result partially supports the previous findings of Lee and Lim [17], who identified the largest effect size at 0.99 for PEPs that lasted 16 sessions and above, while PEPs that lasted 6 to 10 sessions and 11 to 15 sessions had effect sizes of 0.78 and 0.57 , respectively. Previous studies have reported that differences in the effect size according to the number of sessions are not constant [17]. This inconsistent result possibly reflects the characteristics of children and parents, the occupations of the subjects, the distance between subjects' residences to the location of the PEP, the transportation method used by subjects to travel to the educational site, and the parents' willingness to receive education and parenting characteristics. When the number of sessions was lower, the official goal was more likely to be achieved [47], whereas it was difficult for attendees to maintain their application of programs' concepts when PEPs for North Korean defectors and their families exceeded 20 sessions, leading to non-cooperation [47]. However, in this study, since the effect size of continuous and long-term education programs lasting 19 sessions or more was found to be large, we recommend adjusting the number of sessions according to the specific situation and subjects. It is difficult, however, to meaningfully compare our findings with those of other studies due to the small number of studies included in our meta-analysis and inaccurate data on the number of sessions in other studies. Thus, the number of sessions of PEPs should be determined by thoroughly surveying the participants' needs, environments, and conditions in order to provide recipient-centered support.

The effect size of PEPs according to the research design was as large as 0.86 for similar experimental studies and 0.87 for single-group pretest-posttest studies, and there was a statisti- cally significant difference between them and the effect size of RCTs (0.51). An explanation for this is that the desired results may have been achieved through close feedback from a moderator or expert in non-RCTs. Therefore, we must carefully interpret the differences in effect sizes observed in this study.

There were no statistically significant differences in the effect sizes of PEPs according to whether the published work was a thesis (0.64) or academic article (0.61). This finding is consistent with that of a previous study [46]. However, these results should be interpreted with caution, as the findings of existing studies are inconsistent. Some studies found no significant differences in the effectiveness of PEPs according to the type of publication, while others have found greater effect sizes of PEPs in theses [48].

In addition, despite the availability of massive amounts of high-quality parenting education materials, the challenges of learning the language of a new society cannot be neglected. The content of PEPs often contains advanced vocabulary and linguistic structures that make it difficult for non-native speakers to fully understand and utilize the materials unless they have lived in a new area for a long time. An integrated teaching method, in which learners are provided with an explanation in the introduction and engage in activities during the main session, enables immediate feedback and facilitates interactions that help the participants feel comfortable. Even if the participants are not fluent in the language, they can participate by seeing a sample or model, thereby engaging them in the program. Since interactions, intimacy, and engagement increase learners' motivation to participate in educational activities, these teaching methods are more effective than language-intensive lecture-based teaching methods [9]. Although we did not analyze the moderating effects in this study, subsequent studies should also consider examining teaching methods to develop more systematic and practical education programs.

This study had several limitations. First, we only searched for studies published within a specific period in our systematic review, and some unpublished studies may have been excluded. Furthermore, we only included studies published in English or Korean, so it is possible that the study findings predominantly reflect information from cultures that use these specific languages. Of the 23 studies included in the systematic review, only 19 were included in the meta-analysis. Thus, it is possible that the effect sizes of PEPs have been overestimated or underestimated, and caution should be used when interpreting the results. Next, we used statistics measured immediately after interventions when analyzing the effects of PEPs and thus could not examine the long-term effects of interventions. In addition, we only used observer-reported or self-reported parental outcome measures, so we could not examine whether interventions led to other changes in pa- 
rents and children. In the present study, RCTs, quasi-experimental studies, and one-group studies were included in the analysis, which led to a high degree of heterogeneity in the effect sizes of PEPs. The studies included in the meta-analysis used diverse instruments to measure their outcome variables. The types of interventions also varied, including two or more mixed interventions that contained lectures, information delivery, counseling, and behavioral therapy. This limited our ability to identify the factors that contributed to the differences in the effect sizes between different types of interventions. In addition, since there have been only a handful of studies on North Korean refugees and migrants in Korea, there are limitations with regard to the application of our findings. Therefore, communities that attempt to develop PEPs for this population should carefully select educational content that is tailored to the target population, a suitable intervention duration, and an appropriate number of sessions. Subsequent studies should also examine the effect sizes of PEPs according to the educational goals and contents. In the present study, we could not examine teaching methods as a moderator in most studies due to the diversity of intervention-related factors including hands-on activities, presentations, play activities, and discussions, with the exception of one. Future studies should also conduct separate analyses for different intervention methods. Moreover, a meta-analysis should also be conducted to examine the degree to which PEPs promote positive changes, not only in parents but also in children. Despite these limitations, however, this study was still able to conduct an insightful analysis of education intervention studies on refugee and migrant parents in South Korea and abroad. In addition, we analyzed data using meta-analysis of variance and systematically confirmed that PEPs are effective. Therefore, this study is significant since it presents evidence to support the development and implementation of diverse PEPs for refugee and migrant parents.

\section{CONCLUSION}

This study systematically reviewed international and domestic studies on PEPs for refugee and migrant parents, who tend to be socioeconomically vulnerable, and compared and analyzed the effect sizes of PEPs on positive and negative parenting outcome variables. PEPs were found to improve parenting efficacy, positive parenting behaviors, and parent-child relationships, and they relieved parenting stress. Moderating variables were selected that could systematically explain the differences and heterogeneity of the effects of PEPs observed in the studies included in the meta-analysis. The characteristics of participants, the ages of children, the participation of child, the number of intervention sessions, and the research design were the moderating variables that affected the homogeneity of the effect sizes of PEPs. PEPs were found to be most effective for mothers of preschool-aged children and when they lasted for more than 19 sessions. When children are young, it is difficult for parents to routinely participate in education programs as they raise their children, which may undermine the effectiveness of programs. Thus, PEPs should be offered to prospective parents, and PEPs that are tailored to children's growth and development should be readily available to increase parents' confidence and efficacy concerning their parenting roles. In particular, providing PEPs to single-parent families or refugee and migrant mothers will help children in their families adjust to a new society and encourage healthy growth and development.

With the increasing number of refugees and migrants worldwide, family structures are becoming more diverse, and many refugee and migrant parents experience difficulties in their parental roles. In addition, the proportion of separations, reunifications, and new family compositions is increasing. This study is significant in that the effect sizes of PEPs were calculated in a systematic review of studies on refugee and migrant parents. However, most studies on education interventions for refugee or migrant parents were non-RCTs due to several practical limitations. Therefore, the effect sizes calculated in this study must be interpreted with caution. Moreover, the outcome variables were only measured using self-reported questionnaires, which should be addressed by future studies, and future studies should also control for confounding variables in the evaluation of the outcomes. Lastly, only 19 studies were included in the final analysis (with 29 outcome variables for the extraction of the effect size), which may limit the ability to generalize the results to all refugee and migrant parents. Nevertheless, this study exclusively analyzed the effects of PEPs for refugee and migrant parents, who tend to be socioeconomically vulnerable. This study is meaningful due to its differences from previous meta-analysis studies on PEPs.

\section{ORCID}

In-Sook Lee

https://orcid.org/0000-0003-4156-9685

Eunjung Kim

https://orcid.org/0000-0002-4664-9847

\section{Authors' contribution}

Conceptualization: all authors; Data collection: In-Sook Lee; Formal analysis: all authors; Writing-original draft: In-Sook Lee; Writing-review and editing: all authors; Final approval of published version: all authors. 


\section{Conflict of interest}

No existing or potential conflict of interest relevant to this article was reported.

\section{Funding}

This study was supported by a National Research Foundation of Korea (NRF) grant funded by the Korean government (No. NRF-2019R1C1C1003087).

\section{Data availability}

Please contact the corresponding author for data availability.

\section{Acknowledgements}

None.

\section{REFERENCES}

1. Sanders MR, Kirby JN, Tellegen CL, Day JJ. The Triple P-Positive Parenting Program: a systematic review and meta-analysis of a multi-level system of parenting support. Clinical Psychology Review. 2014;34(4):337-357. https://doi.org/10.1016/j.cpr.2014.04.003

2. Kim E. Intergenerational acculturation conflicts and Korean American parents' depression symptoms. Issues in Mental Health Nursing. 2011;32(11):687-695.

https://doi.org/10.3109/01612840.2011.597017

3. Lee IS, Park HR, Park HJ, Park YH. Relationships between parenting behavior, parenting efficacy, adaptation stress and post traumatic stress disorder among mothers who defected from North Korean. Child Health Nursing Research. 2010;16(4):360-368.

https://doi.org/10.4094/jkachn.2010.16.4.360

4. Kim GS. Current development status of the parent education program and an analysis of the program. Journal of Parent Education. 2017;9(4):273-292.

5. Lee IS, Jeon JH. Influence of parenting efficacy, parenting stress, and acculturation stress on parent-child relations among North Korean refugee mothers. Child Health Nursing Research. 2021;27 (2):171-180. https://doi.org/10.4094/chnr.2021.27.2.171

6. Jeong $\mathrm{OH}$. Development of mother-child interaction program to enhance psychological adjustment of the children of North Korean defectors [dissertation]. Seoul: Seoul Women's University; 2006. 1-139.

7. Koniak-Griffin D. Maternal role attainment. Image: Journal of Nursing Scholarship. 1993;25(3):257-262.

https://doi.org/10.1111/j.1547-5069.1993.tb00791.x

8. Churchill H, Clarke K. Investing in parenting education: a critical review of policy and provision in England. Social Policy and Soci- ety. 2009;9(1):39-53. https://doi.org/10.1017/S1474746409990182

9. Cho EY, LeeSD. A meta-analysis on the effects of multicultural parent education program. Journal of Learner-Centered Curriculum and Instruction. 2020;20(7):377-396.

https://doi.org/10.22251/jlcci.2020.20.7.377

10. Kim MK, Kim KE. Relationships among perceived social support, self-esteem, parenting attitudes of mothers and children's social competence in multicultural families: the mediating role of parenting attitudes. Korean Journal of Child Studies. 2009;30(5):119-135.

11. Kim E, Cain K, Boutain D, Chun JJ, Kim S, Im H. Pilot study of the Korean Parent Training Program using a partial group-randomized experimental study. Journal of Child and Adolescent Psychiatric Nursing. 2014;27(3):121-131.

https://doi.org/10.1111/jcap.12071

12. Chung KS, Yoo MS, Cha JR, Park HK. A study on the effects of parent education programs for parents with young and school-age children through meta-analysis. Journal of Korean Child Care and Education. 2013;9(3):365-387.

13. Renzaho AM, Green J, Mellor D, Swinburn B. Parenting, family functioning and lifestyle in a new culture: the case of African migrants in Melbourne, Victoria, Australia. Child and Family Social Work. 2011;16(2):228-240.

https://doi.org/10.1111/j.1365-2206.2010.00736.x

14. Huang H, Lee Y. A review of parents' education programs for multicultural families in Korea. Journal of Education and Culture. 2015;21(6):287-320. https://doi.org/10.24159/joec.2015.21.6.287

15. Troy V, McPherson KE, Emslie C, Gilchrist E. The feasibility, appropriateness, meaningfulness, and effectiveness of parenting and family support programs delivered in the criminal justice system: a systematic review. Journal of Child and Family Studies. 2018;27 (6):1732-1747. https:// doi.org/10.1007/s10826-018-1034-3

16. Isaacs SA, Roman NV, Savahl S, Sui XC. Using the RE-AIM framework to identify and describe best practice models in family-based intervention development: a systematic review. Child and Family Social Work. 2018;23(1):122-136. https://doi.org/10.1111/cfs.12380

17. Lee J, Lim SA. Meta-Analysis on the effect of parent education program. Korean Journal of Educational Research. 2020;58(3):117-143. http:// doi.org/10.30916/KERA.58.3.117

18. United Nations High Commissioner for Refugees. 'Refugees' and 'migrants' [Internet]. Seoul: UNHCR Korea; 2016 [cited 2021 September 10]. Available from:

https://unhcr.or.kr/unhcr/program/board/detail.jsp?boardTyp eID $=8 \&$ searchSelect $=\&$ keyWord $=\&$ currentPage $=1 \&$ menuID $=\& \mathrm{fi}$ nishIsYN=\&boardID $=7687 \&$ boardCategory $=\% \mathrm{EA} \% \mathrm{~B} 3 \% \mathrm{~B} 5 \% \mathrm{EC}$ $\%$ A7\%80\&mode $=$ detail

19. NANCEN Refugee Right Center. Statistics status of refugees in Korea (as of December 31, 2020) [Internet]. Seoul: NANCEN Refugee Right Center; 2021 [cited 2021 March 9]. Available from: https://nancen.org/2166? category $=118980$

20. Cohen J. Statistical power analysis for the behavioral sciences. 2nd 
ed. London: Routledge; 1988. p. 25.

21. Bjørknes R, Manger T. Can parent training alter parent practice and reduce conduct problems in ethnic minority children? A randomized controlled trial. Prevention Science. 2013;14(1):52-63. https://doi.org/10.1007/s11121-012-0299-9

22. Choe HS. The development of a parenting training program for female international marriage immigrant from Southeast Asia (1): a case-study of Filipino. Family and Environment Research. 2010; 48(4):57-70. https://doi.org/10.6115/khea.2010.48.4.057

23. Chung S, Leung C, Sanders M. The Triple P-positive parenting programme: the effectiveness of group Triple $\mathrm{P}$ and brief parent discussion group in school settings in Hong Kong. Journal of Children's Services. 2015;10(4):339-352. https://doi.org/10.1108/JCS-08-2014-0039

24. Garcia-Huidobro D, Diaspro-Higuera MO, Palma D, Palma R, Ortega L, Shlafer R, et al. Adaptive recruitment and parenting interventions for immigrant Latino families with adolescents. Prevention Science. 2019;20(1):56-67. https://doi.org/10.1007/s11121-018-0898-1

25. Chung HJ. A study on development and effects of a christian parenting education program for multi-cultural families: based on North Korean defectors. Faith and Scholarship. 2013;18(2):135-171. https://doi.org/10.30806/fs.18.2.201307.135

26. Kim HY. Effects of filial play therapy on the parenting stress and the behavioral problems of the children of Korean Chinese mother and the process of changes in their relationship [master's thesis]. Chungcheongnam-do: Namseoul University; 2016. p. 1-101.

27. Kim EH, Jun SS, Byun EK. Effects of parent education program on parenting stress and parenting efficacy for mothers with young children in multicultural family. Journal of The Korean Data Analysis Society. 2014;16(2):1031-1043.

28. Kim H. Development and application of parental role improvement mentoring program for married immigrant women [master's thesis]. Busan: Dong-Eui University; 2012. p. 1-103.

29. Lakkis NA, Osman MH, Aoude LC, Maalouf CJ, Issa HG, Issa GM. A pilot intervention to promote positive parenting in refugees from Syria in Lebanon and Jordan. Frontiers in Psychiatry. 2020; 11:257. https://doi.org/10.3389/fpsyt.2020.00257

30. Lau AS, Fung JJ, Ho LY, Liu LL, Gudiño OG. Parent training with high-risk immigrant Chinese families: a pilot group randomized trial yielding practice-based evidence. Behavior Therapy. 2011;42 (3):413-426. https://doi.org/10.1016/j.beth.2010.11.001

31. Lee SL, Peng MS. The effects of group art therapy on mothers of children with special educational needs. Art Therapy. 2017;34(1): 12-19. https://doi.org/10.1080/07421656.2016.1273697

32. Leung C, Tsang S, Dean S. Outcome evaluation of the hands-on parent empowerment (HOPE) program. Research on Social Work Practice. 2011;21(5):549-561. https://doi.org/10.1177/1049731511404904

33. Miller KE, Koppenol-Gonzalez GV, Arnous M, Tossyeh F, Chen A, Nahas $N$, et al. Supporting Syrian families displaced by armed conflict: a pilot randomized controlled trial of the caregiver support intervention. Child Abuse \& Neglect. 2020;106:104512. https://doi.org/10.1016/j.chiabu.2020.104512

34. Osman F, Salari R, Klingberg-Allvin M, Schön UK, Flacking R. Effects of a culturally tailored parenting support programme in Somali-born parents' mental health and sense of competence in parenting: a randomised controlled trial. BMJ Open. 2017;7(12): e017600. http://doi.org/10.1136/bmjopen-2017-017600

35. Ponguta LA, Issa G, Aoudeh L, Maalouf C, Hein SD, Zonderman $\mathrm{AL}$, et al. Effects of the mother-child education program on parenting stress and disciplinary practices among refugee and other marginalized communities in Lebanon: a pilot randomized controlled trial. Journal of the American Academy of Child and Adolescent Psychiatry. 2020;59(6):727-738.

https://doi.org/10.1016/j.jaac.2019.12.010

36. Puffer ES, Annan J, Sim AL, Salhi C, Betancourt TS. The impact of a family skills training intervention among Burmese migrant families in Thailand: a randomized controlled trial. PLoS One. 2017;12 (3):e0172611. https://doi.org/10.1371/journal.pone.0172611

37. Shon S. Development and evaluation of program to enhancement of parenting competence at Kyrgyzstan migrant village [dissertation]. Seoul: Kyung Hee University; 2019. p. 1-157.

38. To SM, Kwok CM, So YY, Yan MW. Parent education for migrant mothers of left-behind children in China: a pilot randomized controlled trial. Family Process. 2019;58(2):318-333.

https://doi.org/10.1111/famp.12369

39. Hebbani A, Obijiofor L, Bristed H. Generational differences faced by Sudanese refugee women settling in Australia. Intercultural Communication Studies. 2009;18(1):66-82.

40. Hebbani AG, Obijiofor L, Bristed H. Acculturation challenges that confront Sudanese former refugees in Australia. Journal of Intercultural Communication. 2012;28.

41. Kim E, Cain KC, Webster-Stratton C. The preliminary effect of a parenting program for Korean American mothers: a randomized controlled experimental study. International Journal of Nursing Studies. 2008;45(9):1261-1273. https://doi.org/10.1016/j.ijnurstu.2007.10.002

42. Kim M, Park IJ. Testing the moderating effect of parent-adolescent communication on the acculturation gap-distress relation in Korean American families. Journal of Youth and Adolescence. 2011;40 (12):1661-1673. https://doi.org/10.1007/s10964-011-9648-4

43. Kim E, Im H, Nahm E, Hong S. Korean American parents' reconstruction of immigrant parenting in the United States. Journal of Cultural Diversity. 2012;21(4):124-132.

44. Kim E, Hong S, Rockett CM. Korean American parents' perceptions of effective parenting strategies in the United States. Journal of Cultural Diversity. 2016;23(1):12-20.

45. Ministry of Gender Equality and Family. Multicultural family parent education program development. Survey Report. Seoul: Ministry of Gender Equality and Family; 2016. Report No.: 


\section{TRKO201900001532.}

46. Lee J, Kim J, Cha D, Lee H. Are parent education programs in South Korea really effective?: a meta-analytic study using journal articles. Journal of Families and Better Life. 2013;31(3):27-47.

47. Cho EY, Lee SD. A meta-analysis of the program for children of multicultural families. Journal of Learner-Centered Curriculum and Instruction. 2019;19(21):407-425.

https://doi.org/10.22251/jlcci.2019.19.21.407

48. Cho B, Lee J. A meta analysis on effects of flipped learning in Korea. Journal of Digital Convergence. 2018;16(3):59-73.

https://doi.org/10.14400/JDC.2018.16.3.059 
Supplement 1. Results from the Risk of Bias Tool for Randomized Controlled Trials
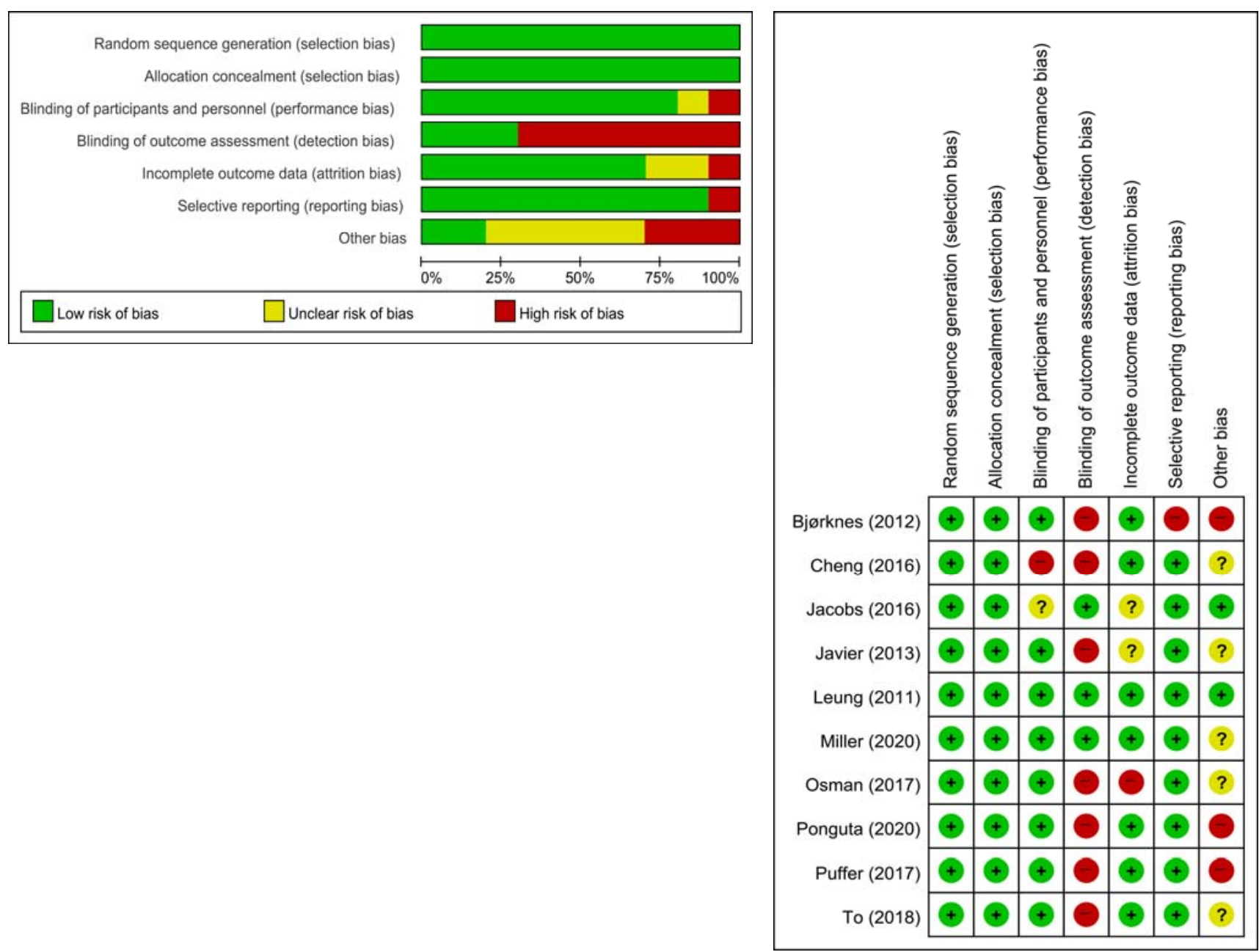
Supplement 2. Results from the Risk of Bias Assessment Tool for Non-Randomized Studies
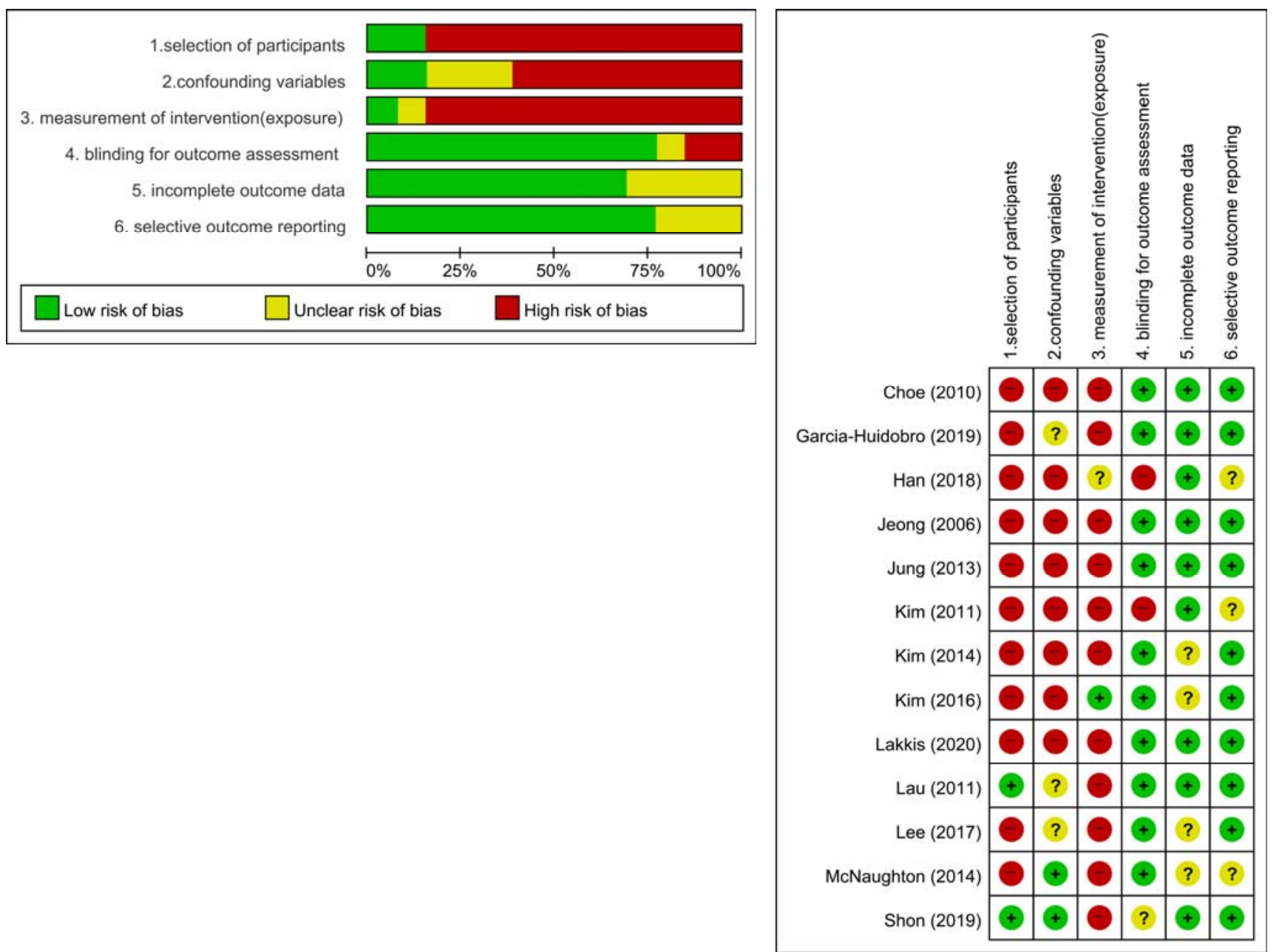